\title{
Feasibility and practicality of replacing hydroelectric dams with wind turbines
}

\author{
Keith A. Rahn ${ }^{\mathrm{a}}$, Aaron Schuff ${ }^{\mathrm{b}}$ \\ ${ }^{a}$ Auburn University, 222 M. Miller Gorrie Center, Auburn, 36849, USA \\ ${ }^{b}$ Auburn University, 118 M. Miller Gorrie Center, Auburn, 36849, USA
}

\begin{abstract}
There is opposition to hydroelectric dams in the Pacific Northwest as they have come to be perceived as damaging to the environment. Of particular concern are the four dams on the Lower Snake River and their detrimental effects to salmon and steelhead spawning habitats. In the last couple of decades, as climate change has come front and center as a global concern, renewable generation methods have become increasingly important. Thousands of megawatts of wind energy have been installed in the Pacific Northwest. With this new influx of generation capacity there is a renewed push to remove the dams, following the logic that the dams can be replaced by wind energy. This research explores whether this is feasible and examines some of the controversies surrounding hydro vs. wind, and also the utility, environmental and economic impacts of each energy generation method.
\end{abstract}

(C) 2018 The Authors. Published by Diamond Congress Ltd., Budapest University of Technology and Economics Peer-review under responsibility of the scientific committee of the Creative Construction Conference 2018.

Keywords: Wind; Energy; Hydroelecticity; Environment; Turbines

\section{Introduction}

The most common forms of renewable, alternative energy used today are wind and solar. These often struggle economically to compete with conventional generation resources. Proponents of alternative energy hope to eventually replace conventional energy generating methods, such as those from combustible fuels with energy generation, in a way that has minimal adverse impacts to the environment. This research will focus solely on energy converted into electrical current for use on public power systems, in particular, the region of the Pacific Northwest. In the Northwest, there currently exists a unique scenario as alternative renewable energy in the form of wind is being sought to replace the conventional renewable energy generation of hydroelectricity.

The Pacific Northwest, with its, rainy, mountainous topography has always been ideal for hydroelectricity. The Columbia River, with its headwaters in the Canadian Rockies flows over 1,200 miles, crossing the United States Border in Washington State and emptying into the Pacific Ocean at Astoria, Oregon. The river's watershed extends across the entire Pacific Northwest, consisting of the majority of Oregon, Washington and Idaho, and stretching as far as Montana, Nevada, Utah and Wyoming (Fig.1). Because of its high flows and steep gradient, the river was surveyed by the United States Government as early as 1932 for its hydroelectric potential and currently produces over $40 \%$ of the total U.S. Hydroelectric generation [13]. 


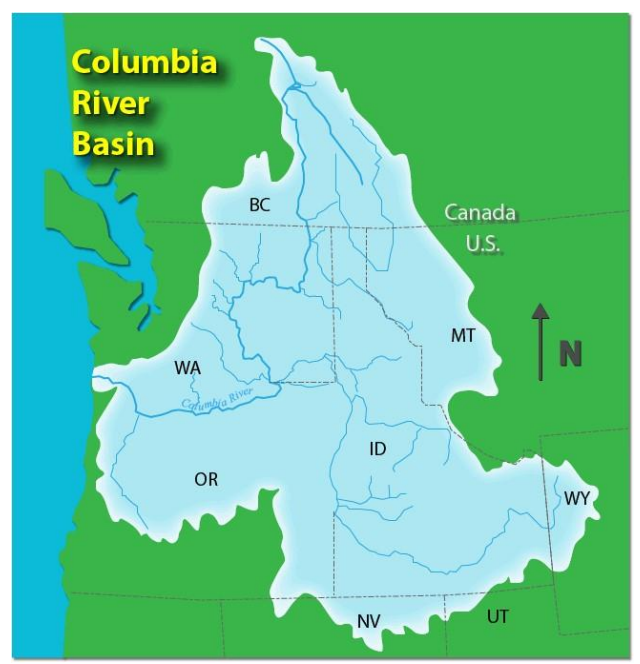

Fig. 1. Map of the Columbia River Basin, covering seven states and two Canadian Provinces. Source: Washington State Department of ecology, 2016

Even while providing low-cost, plentiful and relatively pollution-free electricity, the dams do have a downside. This toll is mostly exacted on the wildlife and fish habitats, in particular, to the salmon and steelhead populations native to the Columbia and Snake rivers. The salmon population in the Columbia River was already in decline due to overfishing, agriculture and other man-caused effects when Grand Coulee, one of the first dams, began construction in the 1930s, as a government sponsored jobs project during the Great Depression. This massive power plant, the largest in the United States by capacity, constructed nearly 600 river miles from the sea, halted salmon runs for hundreds of miles into the upper reaches of the Columbia.

Since the installation of the dams, there has been political pressure to mitigate the impacts on the salmon and wildlife, ranging from increasing expenditures on salmon recovery efforts to outright removal of the dams. However, the benefits of reliable, low-cost and relatively clean energy have thus far prevailed in public opinion over the most extreme solutions, including partial removal or removal proposals.

In the most recent decades there has been increasing competition between newer wind power and traditional hydro, due primarily to legislative requirements called Renewable Portfolio Standards (RPS) and government incentives to develop alternative energy, all of which are driven by the popular ideal of emission free, renewable energy as well as lobbying from wind power organizations such as AWEA. Over the past decade, wind farms have been rapidly increasing construction of new capacity in the Pacific Northwest, from a few hundred megawatts (MW) in the early 2000 s, to over 7,200 MW presently.

Bonneville Power Administration (BPA), a self-funded Federal agency and transmission authority that serves much of the load in the Pacific Northwest, is in the position of balancing all the generation resources and the loads while trying to maintain stability of the system, address environmental concerns, and maintain low rates for the public utility customers. As wind capacity grows, so does the call from some interests to remove hydroelectric dams, especially the four Federal dams on the Lower Snake River (LSR). Therefore, this raises the, "does it make sense to replace renewable energy with renewable energy?"

\section{Literature Review}

Environmental issues are often economic issues, and as with all issues surrounding how resources should be allocated, tend to be controversial. The introduction of wind power to the Pacific Northwest is no different. With influence from the Federal Government to reach 20\% Wind Energy by 2050 [20] and State Governments in the form of mandates, tax breaks and Renewable Portfolio Standards, as well as opinions of regional politicians, wind energy has expanded greatly in the last decade. 
As more settlers headed west across the Oregon Trail, the Columbia River became more important. Steamboats began to appear on the river, and in the late 1800s Congress commissioned the U.S. Army Corps of Engineers (USACE) to build Cascade Locks to allow river navigation past the dangerous Cascade Rapids. In 1932, USACE identified for Congress 10 locations to build dams along the Columbia River in a document called the " 308 Report." The dams would provide a great deal of electrical energy, converted from the mechanical energy of the steep, swift Columbia River. The dams would also enable navigation of ships far up the river, possibly as far as the Canadian Border, or beyond and provide flood control to communities downstream, such as Portland, Oregon. Since then, all the dams identified by that report have built along the entire river from the Canadian Border to the ocean, effectively taming the entire Columbia River [23].

As construction of dams continued, fisheries that Indian tribes still maintained were flooded and became unusable. Many of the dam sites had to be negotiated in order to begin construction with the sovereign Indian nations which generally allowed the construction for various reasons, usually with some consideration. At the present day, the dams have a generation capacity of over 29,000 MW, the majority owned by Federal Government agencies [13]. The regional issues of the U.S. Government's obligation to the regional tribes is nuanced and extremely complex and generally outside of the scope of this research. This research will simply acknowledge that there is significant legitimate reasoning for removal of power plants in the Columbia Basin for salmon and steelhead as well as cultural preservation.

Some local residents question the need for wind when 69 percent of the BPA controlled system is composed of hydroelectricity, a renewable resource, while others actively promote it [1]. In Washington State, Initiative 937 passed in 2006 which requires that utilities obtain 15\% from renewable resources such as wind and solar, but excluded hydroelectricity, effectively considering it nonrenewable. Oregon followed suit in 2007 with legislation requiring an even more ambitious $25 \%$ renewable requirement and already expanding windfarms saw an even bigger influx of windmills following these legislations [5]. In 2016, Oregon increased its RPS to a 50\% requirement from non-large hydroelectric renewable resources and outlawed coal power.

When compared to hydroelectricity, wind power is very unpredictable. While hydro can be stored behind dams for use on demand, wind is at the complete mercy of the weather. Further, just because the wind is blowing does not mean the turbines can be used. The cut-in speed, meaning the minimum wind speed before a wind generator's breaks can be released and it can begin generation is typically 6 to $7 \mathrm{mph}$ and the maximum is around 50 to $60 \mathrm{mph}$. This leads to challenges with maintaining stable voltages in the system [7]. Often, wind is available when it is needed the least, which leads to having to cease hydro production and even ramp down the slow-responding "baseload" thermal plants, usually comprised of coal, gas and nuclear. Baseload plants must run at 70 to 90 percent of their capacity and cannot readily or significantly adjust or cease output without drastic losses to efficiency [14]. There have been instances when production of wind on the BPA system was so great that it was oversupplied and wind farms were ordered to cease generation, a procedure called curtailment. In some cases, BPA must compensate wind farms for curtailment which wastes generation potential and increases costs [16].

Environmental impacts of wind energy exist but are generally considered acceptable when compared to the conventional methods of generation. Neither wind nor hydro are completely carbon free. While wind turbines emit a relatively low amount of carbon throughout their lifecycle, mostly from materials production, manufacture, installation, operations and maintenance and disposal; it is unreasonable to suppose they have no effect on the environment. In fact, a number environmental scientists, while recognizing the low emissions of wind energy, urge procedure with caution when it comes to the impacts of widespread windmills [18,22]. The amount of carbon emissions, created by windmills, while not affected by the size of the windmills, is dependent on a number of factors, and not completely certain [6].

Common downsides associated with wind energy include land use, affected wildlife habitats, unsightliness and health concerns from sound and vibration [18]. Researchers for The Journal of Applied Ecology, British Ornithologists' Union, and The Ecological Society of America have found that windmills have a significant and adverse effect on birds [3,9] and bats [12]. Studies following the impacts on migration and other effects of large wind farms on larger wildlife in the Pacific Northwest are not common and may not be particularly useful given the relative newness of large scale windfarms. It is reasonable to expect that future studies will be conducted into the subject.

According to a pioneering study done by MIT researchers published in 2010, large scale wind farms raise the surface temperature of the earth and affect climate [22]. Following studies have shown that windmills can and do heat the 
vicinity of the windfarm by mixing warmer air with the cold air that stays close to the earth's surface, especially at night. Up to 250,000 acres of wind farms are necessary to replace the four LSR dams. The above environmental impacts by wind turbines are not unique to the Pacific Northwest, generally speaking, although the specific effects they may have on the Northwest ecosystem are a topic of research unto itself. One environmental impact of wind power that is unique to the BPA system are the adverse effects of not using hydroelectric storage on the Columbia River Watershed for generation. If water is not used for generation it must be spilled, which causes greater amounts of dissolved nitrogen gas to fill the river. This is harmful to fish populations [2,4]. Debatably, wind is not to blame for this problem at all, the dams, and of particular interest to this research, the LSR power plants, are. However, wind power has halted some workaround practices, such as generation through certain hydro power plants that have been in place to deal with the oversupply situation which now causes a need for curtailment.

Arguably, this may be the best reason to remove the LSR dams. In fact, there has been a push for several decades to remove dams in the Pacific Northwest, especially the four dams on the lower Snake River, in hopes of restoring the habitats of salmon. Due to political pressure, the U.S. Army Corps of Engineers was ordered to investigate the feasibility of removing the dams in 1995. After a seven-year effort of economists, scientists and engineers, the study was released in 2002. Removing the dams will create its own environmental impacts. The study predicts overall improvements to fish survival in the long term by removing the dams, but also notes there are uncertainties and risks associated with dam removal, with degradation of the river system in the short term [19]. The majority of wind capacity, RPS, Federal and State goals in regards to wind power were realized after this study, so participants in the study could not foresee and did not implement those outcomes into the findings.

\section{Methodology}

Qualitative research methods were used to assess the politics behind the arrival of wind power to the Pacific Northwest and whether the public actually wants wind power to replace hydroelectricity. Hydroelectricity and wind power in the Northwest is a very complex issue and there are numerous aspects to public opinion. News articles and opinions are taken from newspapers generally considered reputable such as The Oregonian, a Portland, Oregon based newspaper which covers many of the issues facing the region's electricity as well as BPA, The New York Times and Forbes. Tying it all together, editorials from energy technologists and environmentalists were analyzed to discuss the merits (as well as demerits) of wind power in a region where there is primarily another source of renewable energy.

In general, the question being asked relative to public opinion of dam removal or wind energy is, "Which, if either, does the public really want?" whether that desire is more renewable energy, more economical energy, less impact on the Lower Snake River System, or something else altogether. The few comprehensive polls that are available and considered trustworthy were analyzed. Opinion pieces were examined, and where possible the background of the opinion piece authors was researched. By necessity, some subjective judgments may be made on the motivation behind certain political issues based on the best available evidence.

Quantitative analysis was completed using the information on generation that BPA makes available to the public to determine what sources have been utilized historically. Historical generation data retrieved from BPA's website, was compiled and organized. The data consists of the total load on BPA's system, and the number of megawatts generated by thermal, hydro and wind from 2007 to present. Most power plants describe themselves by their capacity. That is, the maximum amount of power they can produce under ideal conditions. Capacity factor is the amount power plants actually produce divided by their capacity. A challenge arises with new wind capacity being added yearly and, in some cases, monthly, the data doesn't show the time and date that each windmill went online to the BPA system, making the actual wind capacity of the system difficult to determine.

Intermittency were observed by comparing times of above average loads to times when below average wind is being generated. Conversely, times of high wind generation will be compared against times of low demand. Further, times when all wind on the system are generating less than $100 \mathrm{MW}$, which is the approximate output of one, small, hydro unit at an LSR power plant were measured and charted for clarity.

In order to compare which electricity generation method is cheaper, new wind, or hydroelectricity from existing power plants, it is useful to use the Levelized Cost of Electricity (LCOE). Doing so requires a number of assumptions. The U.S. Energy Information Administration provides data for building new hydro capacity. The LSR power plants have been in operation since 1962, 1969, 1970 and 1975. Economic life of the investment is variable for both energy 
generation sources. For wind, a life of 20 years will be assumed [11]. For hydro, assuming an economic lifespan becomes a bit more complicated since a dam is constructed of many components with vastly different lifespans. 40 to 80 years are safe assumptions for the many of components although the structures can last in excess of 100 years [10]. Determining a weighted average that is useful and reflective of capital costs and lifespans is beyond the scope of this research.

\section{Data Analysis}

Objective polls on the subject of whether or not the general public supports dam removal are somewhat difficult to find. The public tends to be generally positive toward the idea of renewable wind power, but negative toward the idea of removing dams. Thus, there exists a challenge in this disconnect, and discovering if the public would truly rather be supplied electricity by wind farms rather than dams. A poll by Earthfix and DHM Research done in 2011 with a sample size of 1,200 people divided evenly between Idaho, Oregon and Washington found that support of water quality is the highest priority. The Earthfix study also gives insight into how people viewed wind power. On average, study participants estimated that 8.4 percent of electricity comes from wind, but believe that wind energy should provide $18.6 \%$. In reality, according to the data from BPA, 7.3 percent was provided by wind in 2011 . The regional public also believed that hydroelectricity should be reduced from their perceived percentage of $41.4 \%$ (reality $67.4 \%$ in 2011) to a target of $29.8 \%$ [8]. Thus the public generally misunderstands where electricity comes from, apparently unaware of how much is produced by hydro in the region. A chart demonstrating the production trends over this period of time is shown in Fig. 2. The overall average production of wind, hydro and thermal between 2007 and 2016 is 7.5, 67.7 and 24.8 percent respectively.

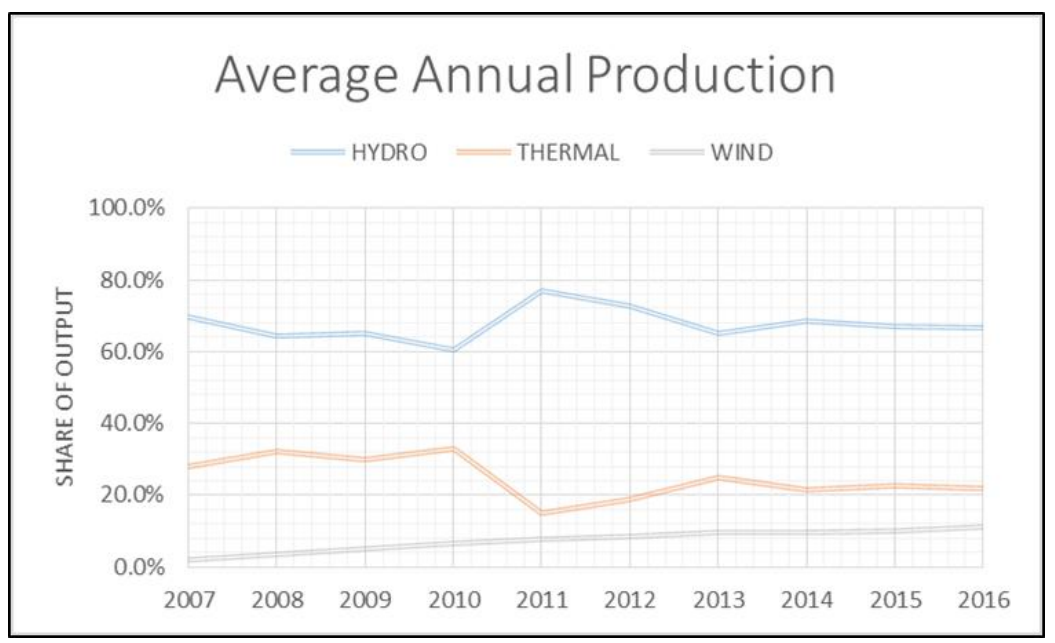

Figure 2: Average output shares of generation output since 2007 Source: US Energy Information Administration, $2016 \mathrm{a}$

However, even though the public underestimates how much of their electricity it gets from hydroelectricity, and in spite of its views that hydro should be reduced even further, it does not appear to translate to a desire to remove the Lower Snake River power plants to replace them with hydro. According to the same study, $31 \%$ of the public views removal of the Snake River dams as "extreme" and while 34\% think it is a necessity to "consider whether the dams on the Lower Snake River can be removed to save salmon species in the Northwest without hurting the economy or significantly increasing electric rates." Only $8 \%$ believed in removing the dams immediately "to save salmon species in the Northwest" [17].

Other polls sponsored by Northwest River Partners, a hydropower advocacy group claim that as high as $71 \%$ of respondents view dam removal as extreme, $67 \%$ would not be willing to reduce the amount of hydropower, $69 \%$ believe hydropower does not contribute to climate change and $88 \%$ view hydropower as a renewable resource similar to wind and solar [15]. However, the complete polling questions and methodology was not readily available for review. 
Over 60 percent of the time when there is high load demand, wind power is producing at below average rates. In other words, it's not available when it's needed most. Conversely, when demands are low, such as at night, wind commonly picks up, producing electricity that is unneeded. This is a problem that can result in curtailment. In 2011, high springtime flows required significantly higher than usual springtime generation. When in 2011 and 2012 high flows came simultaneously with high winds grid managers had more than they could handle. Consequently, BPA ordered wind producers to cease production, which deprived them of generation revenues.

Approximately $53 \%$ of the time, wind energy is producing less than $2 \%$ of its capacity on the BPA system, under $100 \mathrm{MW}$, or one generator at one of the LSR power plants (Fig. 3). For this research, this is considered negligible. Hydroelectricity, on the other hand, does not have the same problems (Fig. 4).

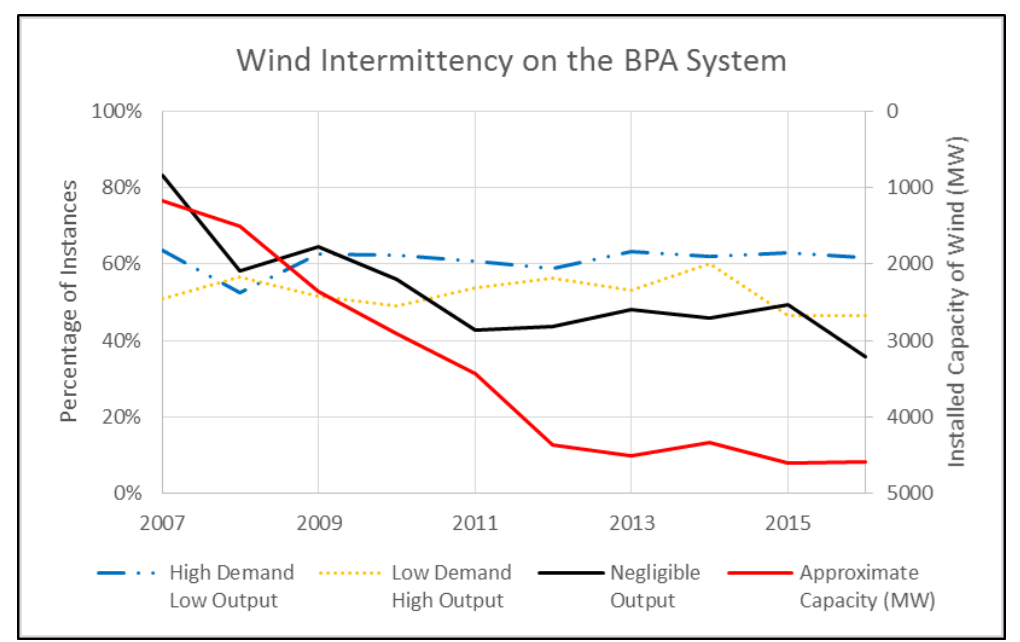

Fig. 3: Wind generation intermittency on the BPA system (2007-2016) Source: US Energy Information Administration, 2016a

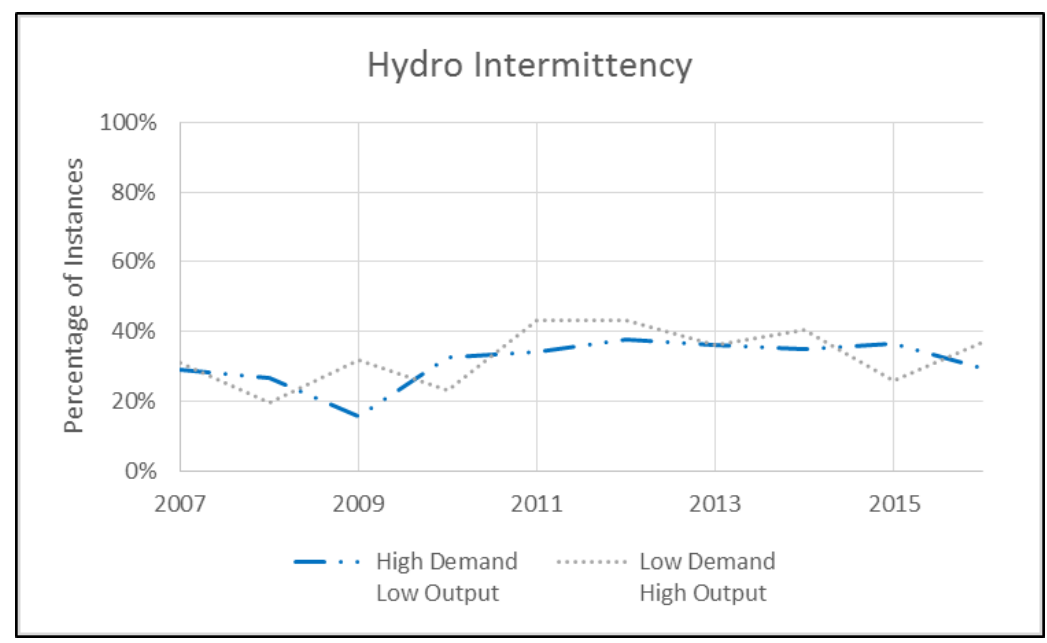

Fig. 4: Hydro generation intermittency on the BPA system (2007-2016) Source: US Energy Information Administration, 2016a

While the generation can vary with the flows of the river, it is relatively stable. Hydro generation is at its lowest in summer, as most of the snowpack is melted and the river flow drops. The reduction in energy generation will then need to be made up by another generation resource, usually thermal. While drought years can cause production to be cut even further, this is somewhat unusual in this region. The percentage of instances when high demand received low output from hydro are below half. Conversely, the number of times when hydro output exceeds the average when 
demand is low is zero. This indicates control over hydroelectricity, and an ability to utilize it, for the most part, when needed. There are no instances of negligible hydro generation on the BPA system.

\section{Conclusion}

Wind power should be appropriately recognized for its merits, which include reduced reliance on fossil fuel consumption. However, wind should not be utilized to replace other forms of renewable power, especially hydroelectric as it is not nearly as reliable and does not provide the additional benefits that hydro dams provide. Public opinion does not warrant removal of the dams at this time as indicated by the limited public opinion materials available at this time. RPS should include hydro, take into account the high costs associated with their implementations, and be practical toward the goal of reducing carbon emissions, pollution, and fuel consumption rather than trying to select preferred renewable technologies.

While there are ways to address the challenges of intermittency of wind, they are not inexpensive. Currently the most practical way of dealing with these challenges on the BPA system is to continue to utilize the LSR power plants to balance transmission. In the future, pumped storage and compressed air technologies may become necessary to utilize as well. There are benefits to the environment of the Pacific Northwest to remove the LSR dams, in the form of fish and wildlife improvements which may improve the overall ecology of the region. However, replacement with wind resources may offset some of the benefit to the environment due to large amounts of land use, and possible climate alteration. The fossil fuel burning plants required to compensate for the loss of the LSR power plant capacity will result in greater greenhouse emissions than exist currently.

It is not currently cost effective, nor is it ever likely to become so to replace existing hydro capacity with new wind. Storage solutions will reduce the intermittency disadvantage of wind, and can likely reduce some long-term costs as well, but will still have capital and O\&M costs associated. Therefore, due primarily to high costs loss of stability to the BPA system, the replacement of renewable hydro generation by fossil fuels, with unclear benefits to show for it, this research concludes that the Lower Snake River power plants should not be replaced by wind generation.

\section{References}

[1.] Avakian, B., \& Dingfelder, J. (2016, February 25). Ignore the naysayers and pass the no-coal bill (OPINION). OregonLive.com. Retrieved from

http://www.oregonlive.com/opinion/index.ssf/2016/02/ignore_the_naysayers_and_pass.html

[2.] Backman, T., \& Evans, A. (2002). Gas Bubble Trauma Incidence in Adult Salmonids in the Columbia River Basin. North American Journal of Fisheries Management, 579-584.

[3.] Barrios, L., \& Rodriguez, A. (2004). Behavioural and environmental correlates of soaringbird mortality at onshore wind turbines. Journal of Applied Ecology, (41), 72-81.

[4.] Beiningen, K., \& Ebel, W. (1968). Effect of John Day Dam on Dissolved Nitrogen Concentrations and Salmon in the Columbia River. Retrieved October 16, 2016, from file:///D:/School/zzCapstone\%20Paper/Environmental/918-2016_Effect\%20of\%20.pdf

[5.] Bonneville Power Administration. (2016). FY 2017 Congressional budget - draft - FY-2017-CongressionalBudget.pdf. Retrieved from https://www.bpa.gov/Finance/FinancialInformation/Documents/FY-2017-CongressionalBudget.pdf

[6.] Crawford, R. H. (2009, July 6). Life cycle energy and greenhouse emissions analysis of wind turbines and the effect of size on energy yield. University of Melbourne, Melbourne, Australia. Retrieved from

file:///D:/School/zzCapstone\%20Paper/Environmental/Life\%20Cycle\%20Energy\%20and\%20Greenhouse\%20Emissi ons $\% 20$ Analysis $\% 20$ of $\% 20$ Wind $\% 20$ Turbines $\% 20$ and $\% 20$ the $\% 20$ Effect $\% 20$ of $\% 20$ Size $\% 20$ on $\% 20$ Energy $\% 20$ Yiel d.pdf

[7.] Datta, R., \& Ranganathan, V. T. (2002). Variable-speed wind power generation using doubly fed wound rotor induction machine-a comparison with alternative schemes. IEEE Transactions on Energy Conversion, 17(3), 414421. https://doi.org/10.1109/TEC.2002.801993

[8.] DHM Research. (2011). EarthFix Survey Web Version. Retrieved October 28, 2016, from

file:///D:/School/zzCapstone\%20Paper/EarthFix\%20Survey\%20Web\%20Version.htm

[9.] Drewitt, A., \& Langston, R. (2006). Assessing the impacts of wind farms on birds - Assessing the impacts of wind farms on birds.pdf. British Ornithologists' Union, 148, 29-42.

[10.] IRENA. (2012a, June). Renewable Energy Cost Analysis: Hydropower. Retrieved November 11, 2016, from 
http://www.irena.org/documentdownloads/publications/re_technologies_cost_analysis-hydropower.pdf [11.] IRENA. (2012b, June). Renewable Energy Cost Analysis: Wind Power. Retrieved November 12, 2016, from https://www.irena.org/DocumentDownloads/Publications/RE_Technologies_Cost_Analysis-WIND_POWER.pdf [12.] Kunz, T., Arnett, E., Erickson, W., Hoar, A., Johnson, G., Larkin, R., et al. (2007). Ecological impacts of wind energy development on bats: questions, research needs, and hypotheses. The Ecological Society of America, 5(6), $315-324$

[13]. Lillis, K. (2014, June 27). The Columbia River Basin provides more than $40 \%$ of total U.S. hydroelectric generation - Today in Energy - U.S. Energy Information Administration (EIA). Retrieved October 24, 2016, from https://www.eia.gov/todayinenergy/detail.php?id=16891\#

[14.] Nelder, C. (2012, March 28). Why baseload power is doomed. Retrieved October 23, 2016, from http://www.zdnet.com/article/why-baseload-power-is-doomed/

[15.] Preusch, M. (2011, May 6). Poll: Northwest voters oppose Snake River dam removal. OregonLive.com. Retrieved from http://www.oregonlive.com/environment/index.ssf/2009/04/poll_northwest_voters_oppose_s.html [16.] Sickinger, T. (2012, February 7). BPA offers to split costs when it pulls the plug on wind farms.

OregonLive.com. Retrieved from

http://www.oregonlive.com/business/index.ssf/2012/02/bpa_offers_to_split_costs_of_c.html

[17.] Steves, D. (2011, December 9). Survey Finds Consensus On Better Salmon Habitat But Not On Dam Removal. Retrieved October 29, 2016, from http://www.opb.org/news/article/survey-finds-agreement-for-helping-salmonwith-hab/

[18.] Union of Concerned Scientists. (2013, March 5). Environmental Impacts of Wind Power. Retrieved October 17 , 2016, from http://www.ucsusa.org/clean_energy/our-energy-choices/renewable-energy/environmental-impacts-windpower.html

[19.] U.S. Army Corps of Engineers, W. W. D. (2002, February). Improving Salmon Passage - Lower Snake River Juvenile Salmon Migration Feasibility Report/Environmental Impact Statement. Retrieved October 17, 2016, from http://www.nww.usace.army.mil/Portals/28/docs/environmental//srstudy/Summary.pdf

[20.] U.S. Department of Energy. (2008). Wind Vision | Department of Energy. Retrieved October 16, 2016, from http://energy.gov/eere/wind/maps/wind-vision

[21.] U.S. Energy Information Administration. (2016a, June). Cost and Performance Characteristics of New

Generating Technologies, Annual Energy Outlook 2016. Retrieved October 16, 2016, from

https://www.eia.gov/forecasts/aeo/assumptions/pdf/table_8.2.pdf

[22.] Wang, C., \& Prinn, R. G. (2010, February 22). Potential climatic impacts and reliability of very large-scale wind farms. Massachusetts Institute of Technology, Cambridge, MA. Retrieved from

http://news.mit.edu/2010/climate-wind-0312

[23.] Willingham, W. (1992). Northwest Passages: History of the Seattle District U.S. Army Corps of Engineers Volume II 1920-1970. Retrieved October 16, 2016, from

http://www.nws.usace.army.mil/Portals/27/docs/Histories/Final\%20History\%20Vol\%202.pdf 